\title{
Diagnosis of chikungunya virus infection in Baja California Sur, Mexico
}

\author{
Moreno-Legorreta, M. ${ }^{1}$, Tozar-Zamora, I. ${ }^{2}$ and Serrano-Pinto, V. ${ }^{{ }^{*}}$ \\ ${ }^{1}$ Centro de Investigaciones Biológicas del Noroeste, Ave. IPN 195, La Paz, B.C.S. 23096, Mexico \\ ${ }^{2}$ Laboratorio Estatal de Salud Pública, Secretaria de Salud, Ave. de los Deportistas s/n, La Paz, B.C.S. 23085, \\ Mexico \\ *Corresponding author e-mail: vserrano04@cibnor.mx \\ Received 4 March 2020; received in revised form 19 July 2020; accepted 20 July 2020
}

\begin{abstract}
Chikungunya virus infection had not been reported by the National Secretary of Health of the State of Baja California Sur, Mexico before 2015, and until now, no information of the disease has been published. Thus, the objective of this study was to assess the tendency that the disease has shown since its introduction. The total number of cases in the state was analyzed, and the incidence rate of infection was evaluated in the general population, age groups, and gender. From 2015-2019, the year with the highest number of reported cases was 2016 with 210 cases, but no cases were reported from 2018-2019. The gender with the highest number of cases was female. The most affected age group was adults 45-64 years of age.
\end{abstract}

\section{INTRODUCTION}

Worldwide, viral diseases transmitted by vectors are classified as those with the greatest impact on public health. Currently, the World Health Organization (WHO) has classified arboviruses as the priority health problem, considering them the tenth cause of death by infectious diseases in the world since 1998 (WHO, 2020).

As a result of population movement, climate change, vector resistance to insecticides and the mosquito vector capacity to transmit other viruses of public health importance, the chikungunya virus (CHIKV) was identified and considered as emergent because it was able to spread quickly in the American Continent since 2013 (Halstead, 2015). CHIKV contains RNA as genetic material and belongs to the genus Alphavirus of the Togaviridae family.

Chikungunya fever (CHIK) is a condition that can cause acute, subacute, and chronic disease. Acute fever is characterized by symptoms of high temperature of $38.8^{\circ} \mathrm{C}$, headache, severe joint pain, and other symptoms may include backache, dysfunction, myalgia, nausea, vomiting, rash, conjunctivitis, and polyarthritis (DGE, 2017; WHO, 2020). From 2005-2006 Reunion Island experienced a massive outbreak; during this epidemic the possibility of mother-tochild transmission in the perinatal period was revealed, causing infection up to $49 \%$ of newborns with a high morbidity rate (Ramful et al., 2007). Reverse transcriptionpolymerase chain reaction in cerebrospinal fluid was positive in 22 out of 24 cases, and abnormal findings on brain magnetic resonance imaging (14 of 25) with matter lesions or intraparenchymal hemorrhages or both. This serious condition is transmitted by the vector mosquitoes Aedes aegypti and Ae. albopictus (Halstead, 2015).

Carey (1971) who rediscovered Christie's work (Christie, 1881), noted that CHIK pandemics originating in eastern Africa had crossed the Indian Ocean at roughly 40-50-year interval: 1770s, 1824, 1871, 1902, 1923, and 1963-1964 (Carey, 1971). To those 
cycles we can now add 2005-2014.The last two trans-Indian Ocean pandemics occurred in the modern virologic era and have been documented by virus isolation (Halstead, 2015). From 1963-1964, a CHIK epidemic swept down the eastern coast of India from Calcutta to Sri Lanka (Sarkar et al., 1965; Rao et al., 1965; Rao, 1966).

Currently, the wide range of CHIKV seroprevalence worldwide could be explained by many reasons, such as climate factors, vector control measures applied before and during outbreaks that affected Ae. aegypti infestation levels, the previous population immunity level, and CHIKV strain and genotype (Dias et al., 2018). The CHIKV genome sequencing confirmed the spread of an Asian lineage strain from the Caribbean, which suggested that although CHIKV had circulated in the Americas since 2013, no adaptive mutations have occurred (Kautz et al., 2015). In recent years, the population in Mexico has suffered from CHIKV infection. The first confirmed case in the municipality of Tlajomulco de Zúñiga, Jalisco, Mexico in 2014 was imported from the Caribbean islands of Antigua and Barbuda by a 39 year- old woman (Rivera-Ávila, 2014). Kautz et al. (2015) mentioned that $79 \%$ of febrile illness cases with polyarthralgia were caused by CHIKV in Chiapas, Mexico during late 2014 when 222 cases were reported. During 2015, an epidemiological outbreak occurred (12 588 reported cases); however, the number of cases began to decrease (759 cases) in 2016, (64 cases) in 2017, (39 cases) in 2018, (9 cases) in 2019 (SUIVE, 2020).

In each region of the country the disease had behaved differently depending on the geographical characteristics and environmental conditions over time. For example, the state of Baja California Sur (BCS) is in the most isolated and arid region of Mexico (Fig. 1). Despite the emerging history of CHIKV cases in the country, little information had been released of its severity and risks, and the number of cases that had increased in the last few years. These data need to be understood and analyzed to estimate the extent of the public health problem. Therefore, the objective of this study was to assess the incidence rate of CHIKV infection in BCS in the last years.

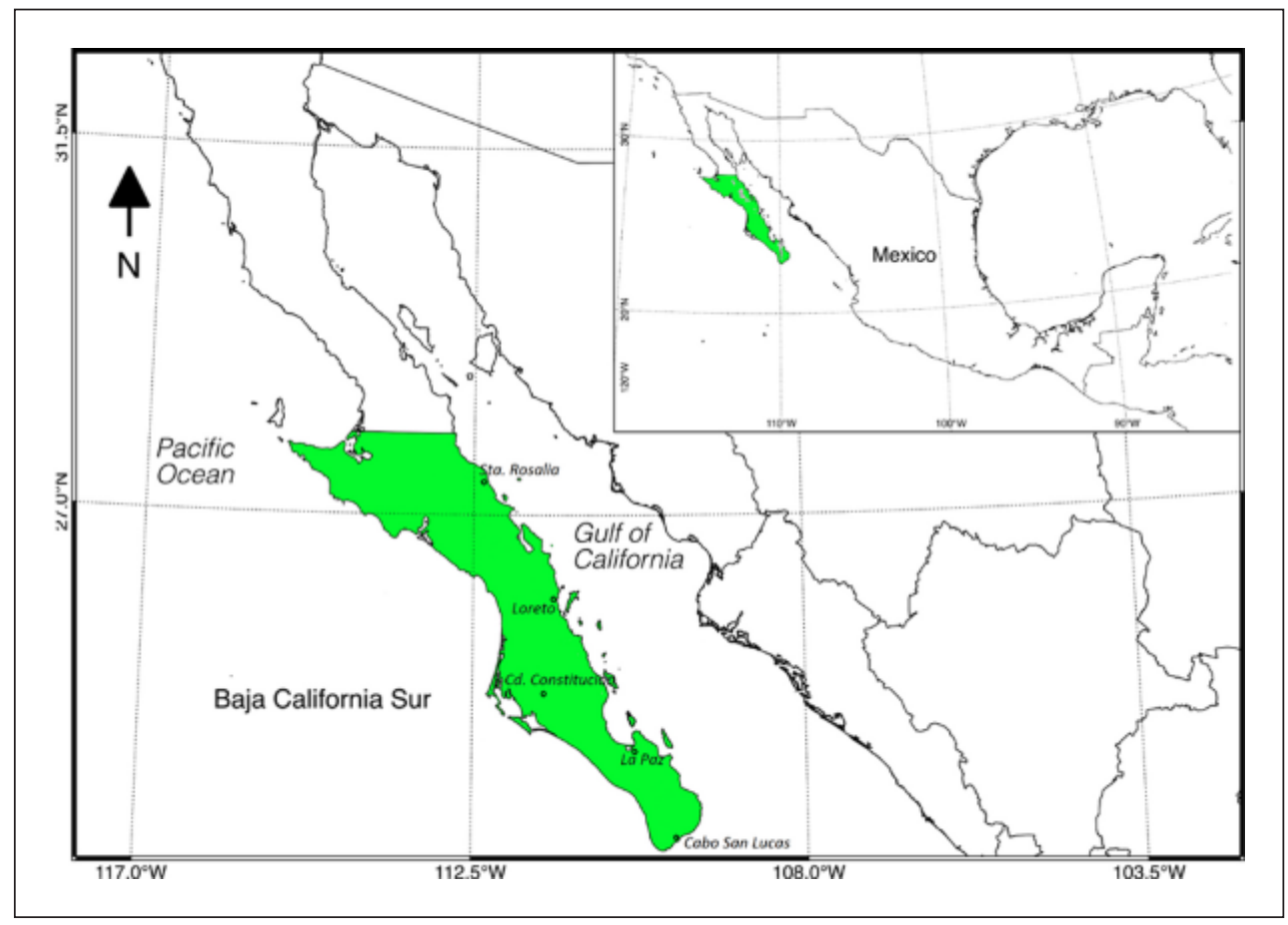

Figure 1. Study area in Baja California Sur, Mexico. 


\section{MATERIALS AND METHODS}

\section{Study population and data}

Chikungunya virus infection data were obtained from online databases Morbidity Yearbooks 1984-2019, National Epidemiological Surveillance System (SUIVE, 2020), related to the total number of cases, incidence rate, gender and age groups.

For Arbovirosis surveillance within the Special Epidemiological Surveillance System of Vector-Transmitted Diseases, all data were confirmed by Chikungunya Diagnostic Algorithm in force according to the Guidelines for Dengue and other Arbovirosis (InDRE, 2017) surveillance. The stages taken into account for disease-based surveillance in the laboratory were Acute and Convalescent: (1) During the acute disease detection phase of viral RNA by real-time RT-PCR in serum samples taken in the first five days of fever onset; (2) During the convalescent phase of the disease (6-12 days after fever started) performing the determination of IgM antibodies in serum sample. In pregnant women, samples were taken six to 30 days from the date of onset of the symptoms, without taking into account the acute phase (DGE, 2017).

\section{Statistical analyses}

For the analyses, Statistica 8.0 software was used to observe tendencies in case numbers for each age group in the study period. Normality tests (KolmogorovSmirnov test) and homogeneity of variance (Levene's test) were used with significance set at $p<0.05$. Incidence data were broken down in seven age groups (Annual average per 100000 inhabitants) following the groups reported by the Health Ministry and analyzed for the general population. One-way ANOVA was conducted on data with significant statistical differences, using post hoc analysis (Fisher's Least Significant Difference Test) to find data with statistical significance. ANOVA was performed within age groups across the years of study.

\section{RESULTS}

Chikungunya virus infection in Baja California Sur was reported in 170 cases from May to December 2015. In 2016, the highest number of reported cases (210) was recorded in January and February, and later from May to November when October was the month with the highest number of cases (110). In 2017, only three cases of CHIKV were reported in January and October, and no cases were reported from 2018-2019 (Fig. 2). From 2015-2017, the gender with the highest number of cases was female (Fig. 2) in 2015 (102/170, 60\%), in 2016 $(140 / 210,66.6 \%)$, and in $2017(3 / 3,100 \%)$ $(p<0.05)$.

Figure 3 shows the incidence graph of the number of CHIKV cases in the different age groups; the statistical analyses showed significant differences among them. The age group from 46-64 years old was the most affected, following those from 5-14, 24-44 and 65 and more years old; the least affected groups were those from 15-24, < 1, 1-4 years old.

\section{DISCUSSION}

The first case of CHIKV infection in BCS was in 2015 (SUIVE, 2020), one year after the presence of the great hurricane Odile that remained motionless throughout BCS for nine days (from 9 to 18 September, 2014); possibly the presence of this climate factor allowed CHIKV to move from other states of Mexico to BCS. During 2016, a greater number of cases were recorded (210 cases). In 2017, the number of cases substantially reduced to three, and no cases were reported from 2018-2019. The significant decrease in cases during these years could have been due to various factors; some of them include the fact that the vector control program implemented in this region has been effective, as well as the increase in preventive measures for public health in schools, educational 


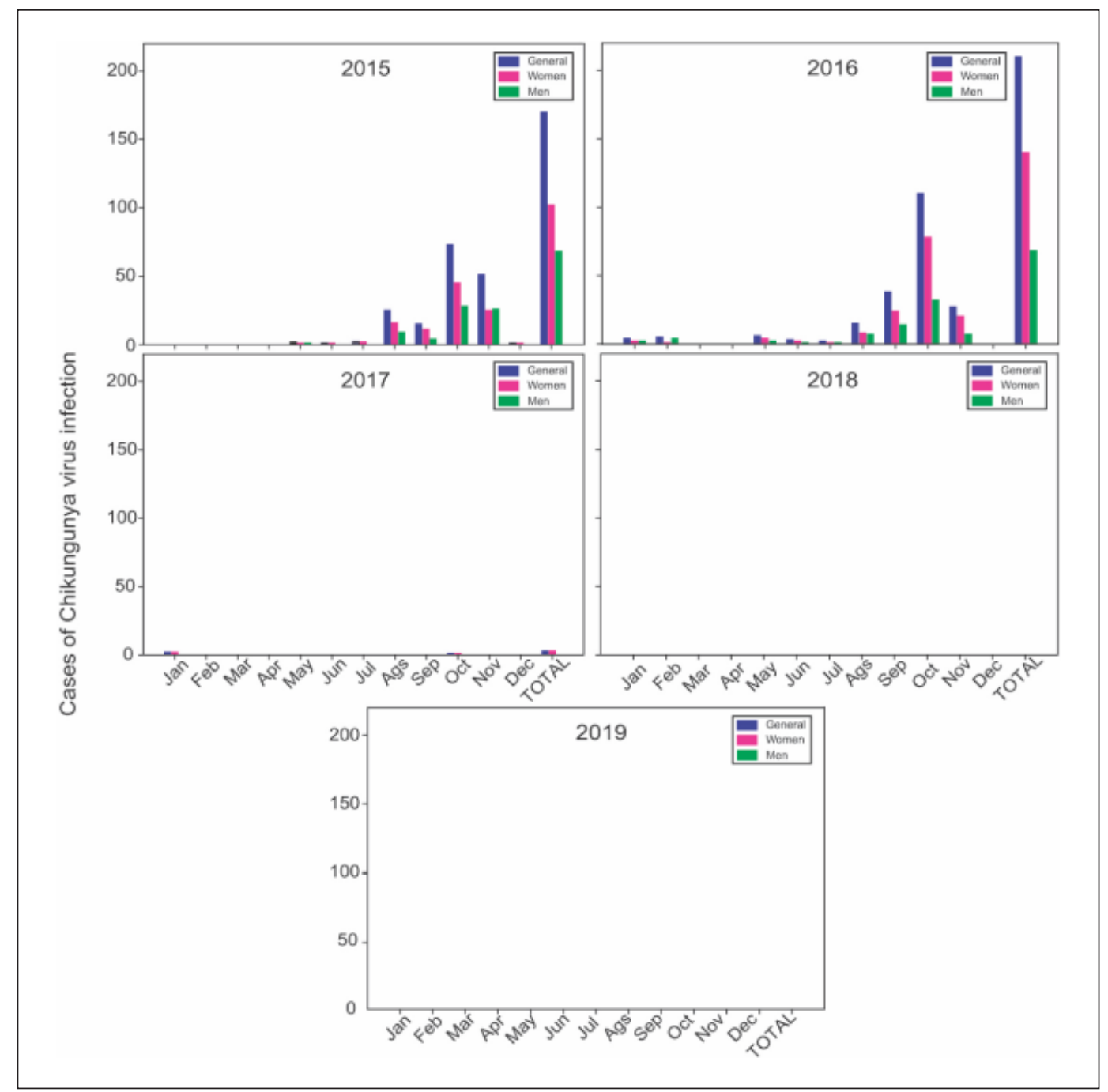

Figure 2. Cases of Chikungunya virus infection in Baja California Sur, Mexico, from 2015-2019.

campaigns in the media, or the absence of intense hurricanes. Comparing our results with those recorded in Mexico, the cases of CHIKV have not only decreased in BCS in recent years but also the number of cases reported in Mexico have been decreasing since 2016 (SUIVE, 2020), possibly for the same reasons mentioned above.

Our results showed that from 2015-2017, women were the most affected gender. A possible explanation could be that women are more exposed to the vector in our region because a large number of them carry out domestic outdoor activities at home, which are the ideal sites for vector reproduction.
Another possibility is the way most women dress in skirts or shorts because this region has very hot temperature during the summer, which is the season with the greatest presence of the vector (Tovar-Zamora et al., 2019). The results in this study were consistent with others, such as those of Dias et al. (2018) in Feira de Santana and RiachaPo do Jacuiìpe, Brazil, where the rate of symptomatic CHIKV infections was significantly higher in women $(54 / 140,38.6 \%)$ than in men $(18 / 80,22.5 \%)$ $(p=0.015)$. These authors mentioned that this difference possibly reflected the levels of previous prevalence of rheumatic diseases in women. In the island of Reunion, France, 


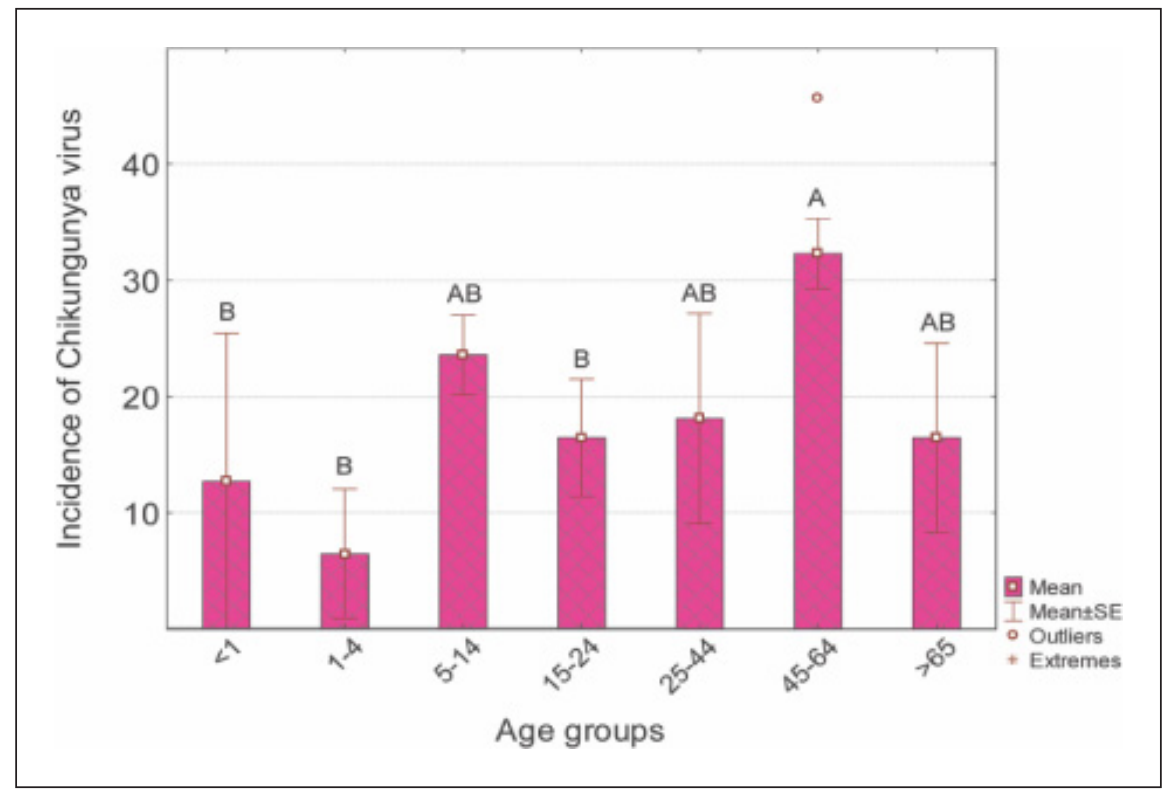

Figure 3. Chikungunya virus infection incidence rate in different age groups recorded in the State of Baja California Sur, Mexico (Annual average per 100000 inhabitants) from 2015-2019.

the infection by the CHIKV from 2005-2006 had also greater affection in women (Renault et $a l .$, 2007). The authors explained that women could be more exposed to the vector because they performed more home and gardening activities, and backyards are especially liable to contain vector breeding sites. Another possible explanation might have been the differences between clothing for men and women regarding skin exposure, especially ankles and legs. Pialoux et al. (2017) mentioned that French health authorities had collated 96 serologically documented cases in Réunion residents who required intensive care; 79 of these patients were adults, and male/female sex ratio was 1.4. In Jamaica in 2014, the Ministry of Health tested blood samples from 137 suspected CHIKV cases by PCR. The cases were predominantly female (59\%) (Duncan et al., 2017).

The incidence in the number of CHIKV cases in the different age groups in this study showed that the adult age group from 46-64 years old was the most affected. This result could be explained because people at that age range may start having medical conditions (high blood pressure, diabetes, autoimmune and rheumatic diseases, heart failure, cancer, etc.), which make them more vulnerable (Duncan et al., 2017; Dias et al., 2018). Mosquitoes could be more attracted to certain chemicals that people with these comorbidities give off because they produce more lactic acid or exhale more carbon dioxide, have higher metabolism, higher body temperature, more body odor (Geier et al., 1996, 1999). The results in this study were similar showing that adults were the most affected group; Carey et al. (1969) mentioned that during the 1964 epidemics in Vellore in southern India, virological and serological studies on 477 fever patients, 275 were adults. In Jamaica during the outbreak peak (August - October 2014), the most affected group was adults from 25-59 years old (62.9\%); hypertension (33.7\%) was the most frequent comorbidity reported (Duncan $e t$ $a l ., 2017)$. Another study in Feira de Santana and Riachão do Jacuípe, Brazil, the rate of symptomatic CHIKV infections were significantly higher in 40-59 and >60 age groups (Dias et al., 2018). In Salvador Bahía, Brazil, considering only the laboratory confirmed CHIK cases, the attack rate was 5.6 cases $/ 100$ adults $\geq 40$ years of age (Tauro 
et al., 2019). In a sero-survey done in Calcutta City, $4.37 \%$ of 379 samples tested positive for CHIKV where the highest rates were observed in the 51-55 age-group, and no cases of seropositivity were detected in the youngest group (Ravi, 2006).

It is important to mention that in BCS, the CHIK number of cases that have been reported were much smaller compared to dengue cases in the same years: 2015 (571 cases); 2016 (367 cases); 2017 (54 cases); 2018 (335 cases), and 2019 (67 cases) (Moreno-Legorreta et al., 2015, Díaz-Castro et al., 2017, Serrano-Pinto et al., 2017, SUIVE, 2020). However, the reason is still unknown since it is the same vector mosquito that transmits both diseases. Further studies are necessary to comment on the possibility of a dengue and CHIKV coinfection since the diagnostic testing algorithm routinely performed in Mexico does not detect both conditions at the same time.

The dissemination strategies for preventive measures for these diseases have been effective in BCS until now. Nonetheless, one of the main limitations continues to be identifying the case in the first contact with medical staff since diagnosis is fundamentally clinical, and only the cases of public hospitals are recorded, leaving out those of private health providers. Therefore, epidemiological criteria must be considered, as well as the presence of vectors Ae. aegypti or Ae. albopictus. Notwithstanding the positive disease data used in this diagnosis were verified by molecular and biochemical analyses; no symptom records were found for each case, and no antibody tests were available to report in this retrospective analysis.

Based on the above, the need to integrate laboratory tests, data from hospitals and clinics, epidemiological surveillance, entomological surveys, and fumigation activities should be reinforced. Additionally, financial support should be obtained to carry out national and international research to develop technologies and strategies that increase the effectiveness of vector control programs, mitigate chronic symptoms of the disease, and develop vaccines that can be applied in vulnerable populations to CHIKV.

\section{CONCLUSION}

Despite the few years of CHIKV infection in BCS, Mexico (2015-2019), this diagnosis allowed us to observe the downward tendency shown since its introduction; nonetheless, additional studies should be performed to validate the CHIKV case definition. The collection of serological samples and their records may provide additional information about this disease and its natural history.

\section{Conflict of Interest}

The authors declare that there is no conflict of interest or financial disclosure about this publication.

Acknowledgement. The authors thank the Departamento de Estadística, Dirección General de Planeación de la Secretaria de Salud, BCS; Departamento de Vigilancia Epidemiológica, Subdirección de Medicina Preventiva de la Dirección de los Servicios de Salud, BCS; and Programa de Vectores de la Secretaria de Salud, BCS for providing data. Diana Fischer for editorial services in English. Funding was provided by the Centro de Investigaciones Biológicas del Noroeste, S.C. (CIBNOR project PPAC-2019).

\section{REFERENCES}

Carey, D.E., Myers. R.M., Deranitz, C.M., Jadhav, M. \& Reuben, R. (1969). The 1964 chikungunya epidemic at Vellore, South India, including observations on concurrent dengue. Transactions of The Royal Society of Tropical Medicine and Hygiene 63: 434-445.

Carey, D.E. (1971). Chikungunya and dengue: a case of mistaken identity? Journal of the History of Medicine and Allied Sciences 26: 243-262. 
Christie, J. (1881). On epidemics of dengue fever: their diffusion and etiology. Glasgow Medical Journal 16(3): 161176.

Dias, J.P., Costa, M.C.N., Campos, G.S., Paixão, E.S., Natividade, M.S., Barreto, F.R., Suely, M., Itaparica, C., Borges Goes, C.S., Oliveira, F.L.S., Santana, E.B., Silva, N.S.J., Brito, C.A.A., Rodrigues L.C., Sardi, S.I., Saavedra, R.C. \& Teixeira, M.G. (2018). Seroprevalence of Chikungunya Virus after Its Emergence in Brazil. Emerging Infectious Diseases 24(4): 617-624.

Díaz-Castro, S., Moreno-Legorreta, M., Ortega-Rubio, A. \& Serrano-Pinto, V. (2017). Relationship between dengue and climate trends in Northwestern Mexico. Tropical Biomedicine 34(1): 157-165.

Dirección General de Epidemiología (DGE). Subsecretaría de Prevención y Promoción de la Salud. (2017). Lineamientos para la Vigilancia Epidemiológica y Diagnóstico por Laboratorio de Fiebre Chikungunya. Secretaría de Salud. http://187.191.75. $115 / \mathrm{g}$ ob mx/salud/documentos/ manuales/36_Manual_ETV.pdf. [Online September, 2019].

Duncan, J., Gordon-Johnson, K.A., TullochReid, M.K., Webster-Kerr, K., CunninghamMyrie, C. \& Ernst, K. (2017). Chikungunya: important lessons from the Jamaican experience. Revista Panamericana de Salud Publica 41: e60.

Geier, M., Sass, H. \& Boeckh, J. (1996). A search for components in human body odour that attract females of Aedes aegypti. In: Bock GR, Cardew G, (ed.) Olfaction in mosquitoes-host interactions. Ciba Foundation Symposium 2000. Chichester 132-148.

Geier, M., Bosch, O. \& Boeckh, J. (1999). Influence of odour plume structure on upwind flight of mosquitoes towards hosts. Journal of Experimental Biology 202: 1639-1648.

Halstead, S.B. (2015). Reappearance of Chikungunya, formerly called Dengue, in the Americas. Emerging Infectious Diseases 21(4): 557-561.
Instituto de Diagnóstico y Referencia Epidemiológicos (InDRE). (2017). https://www.gob.mx/salud/acciones-yprogramas/instituto-de-diagnostico-yreferencia-epidemiologicos-indre. [Online August, 2019].

Kautz, T.F., Díaz-González, E.E., Erasmus, J.H., Malo-García, I.R., Langsjoen, R.M., Patterson, E.I., Auguste, D.I., Forrester, N.L., Sanchez-Casas, R.M., HernándezÁvila, M., Alpuche-Aranda, C.M., Weaver, S.C. \& Fernández-Salas, I. (2015). Chikungunya Virus as Cause of Febrile Illness Outbreak, Chiapas, Mexico, 2014. Emerging Infectious Diseases 21(11): 2070-2073.

Moreno-Legorreta, M., Díaz-Castro, S., OrtegaRubio, A., Tovar-Zamora, I. \& SerranoPinto, V. (2015). Decades of experience in the diagnosis of dengue fever in the Northwest of Mexico. Revista de Investigaciones Clinicas. Clinical Translational and Investigation $\mathbf{6 7}$ : 372-378.

Pialoux, G., Gaüzère, B.A., Jauréguiberry, S. \& Strobel, M. (2007). Chikungunya, an epidemic arbovirosis. Lancet Infectious Diseases 7: 319-327.

Ramful, D., Carbonnier, M., Pasquet, M., Bouhmani, B., Ghazouani, J., Noormahomed, T., Beullier, G., Attali, T., Samperiz, S., Fourmaintraux, A. \& Alessandri, J.L. (2007). Mother-to-child transmission of chikungunya virus infection. Pediatric Infection Diseases Journal 26(9): 811-815.

Rao, R. (1966). Recent epidemics caused by chikungunya virus in India, 1963-65. Science and Culture 32: 215-220.

Rao, T.R., Carey, D.E. \& Pavri, K.M. (1965). Preliminary isolation and identification of chikungunya virus from cases of dengue-like illness in Madras city. Indian Journal Medical Reserach 53: 689-693.

Ravi, V. (2006). Re-emergence of chikungunya virus in India. Indian Journal Medical of Microbiology 24: 83-84. 
Renault, P., Solet, J.L., Sissoko, D., Balleydier, E., Larrieu, S., Filleul, L., Lassalle, C., Thiria, J., Rachou, E., de Valk, H., Ilef, D., Ledrans, M., Quatresous, I., Quenel, P. \& Pierre, V. (2007). A Major epidemic of chikungunya virus infection on Réunion Island, France, 2005-2006. The American Journal of Tropical Medicine and Hygiene 77(4): 727-731.

Rivera-Ávila, R. (2014). Fiebre chikungunya en México: caso confirmado y apuntes para la respuesta epidemiológica. Salud Pública de México 56(4): 402-404.

Sarkar, J.K., Chatterjee, S.N., Chakravarty, S.K. \& Mitra, A.C. (1965). The causative agent of Calcutta haemorrhagic fever: chikungunya or dengue. Bulletin of the Calcutta School of Tropical Medicine 13: 53-54.

Serrano-Pinto, V. \& Moreno-Legorreta, M. (2017). Dengue hemorrhagic fever in the Northwest of Mexico: A two decade analysis. Revista de Investigación Clinica. Clinical Translational and Investigation 69(3): 152-158.

SUIVE/DGE/Secretaría de Salud/Estados Unidos Mexicanos. (2020). Anuarios de Morbilidad 1984-2019. Sistema Nacional de Vigilancia Epidemiológica. Sistema Único de Información de la Dirección General de Epidemiología (DGEPI). Secretaría de Salud. http://www. epidemiologia.salud.gob.mx/anuario/ html/anuarios.html. [Online May, 2020].
Tauro, L.B., Cardoso, C.W., Souza, R.L., Nascimento, L.C.J., dos Santos, D.R., Campos, G.S., Sardi, S., dos Reis, O.B., Reis, M.G., Kitron, U. \& Ribeiro, G.S. (2019). A localized outbreak of Chikungunya virus in Salvador, Bahia, Brazil. Memorias Instituto Oswaldo Cruz, Rio de Janeiro 114: e180597.

Tovar-Zamora, I., Caraveo-Patiño, J., Penilla, R., Serrano-Pinto, V., Méndez-Galván, J., Maeda-Martínez, A., Guerrero-Cárdenas, I. \& Servín Villegas, R. (2019). Seasonal variation in abundance of dengue vector in the southern part of the Baja California Peninsula, Mexico. Southwestern Entomologist 44(4): 885-896.

World Health Organization, Chikungunya. (2020). https://www.who.int/news-room/ fact-sheets/detail/chikungunya [Online March, 2020]. 